\title{
Controls Advanced Research Turbine: Lessons Learned during Advanced Controls Testing
}

K. Johnson, L.J. Fingersh, and A. Wright

Technical Report NREL/TP-500-38130 June 2005

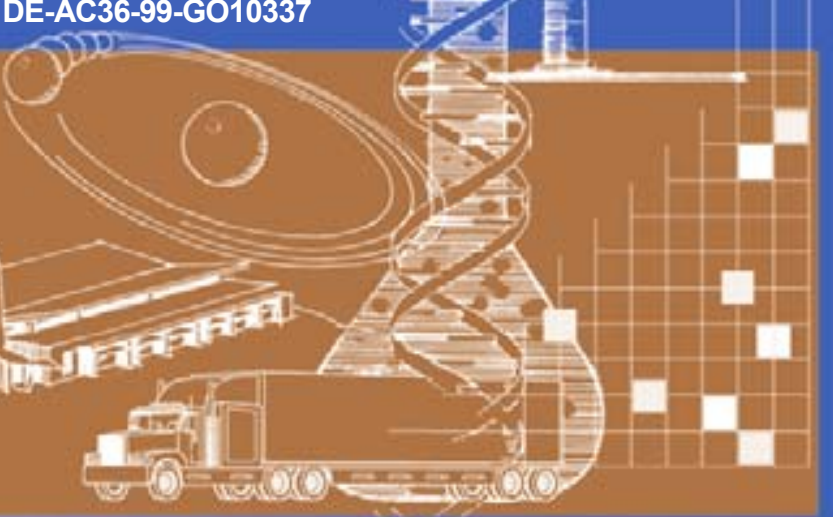




\title{
Controls Advanced Research Turbine: Lessons Learned during Advanced Controls Testing
}

\author{
K. Johnson, L.J. Fingersh, and A. Wright
}

Prepared under Task No. WER5.3112

Technical Report NREL/TP-500-38130 June 2005

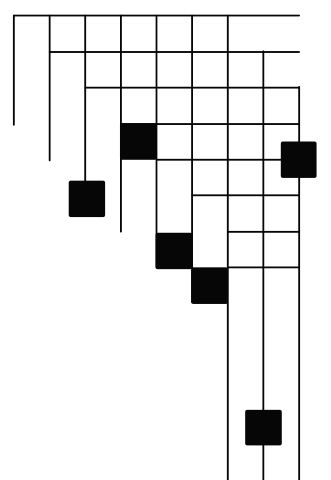




\section{NOTICE}

This report was prepared as an account of work sponsored by an agency of the United States government. Neither the United States government nor any agency thereof, nor any of their employees, makes any warranty, express or implied, or assumes any legal liability or responsibility for the accuracy, completeness, or usefulness of any information, apparatus, product, or process disclosed, or represents that its use would not infringe privately owned rights. Reference herein to any specific commercial product, process, or service by trade name, trademark, manufacturer, or otherwise does not necessarily constitute or imply its endorsement, recommendation, or favoring by the United States government or any agency thereof. The views and opinions of authors expressed herein do not necessarily state or reflect those of the United States government or any agency thereof.

Available electronically at http://www.osti.gov/bridge

Available for a processing fee to U.S. Department of Energy and its contractors, in paper, from:

U.S. Department of Energy

Office of Scientific and Technical Information

P.O. Box 62

Oak Ridge, TN 37831-0062

phone: 865.576 .8401

fax: 865.576 .5728

email: mailto:reports@adonis.osti.gov

Available for sale to the public, in paper, from:

U.S. Department of Commerce

National Technical Information Service

5285 Port Royal Road

Springfield, VA 22161

phone: 800.553.6847

fax: 703.605.6900

email: orders@ntis.fedworld.gov

online ordering: http://www.ntis.gov/ordering.htm 


\section{Contents}

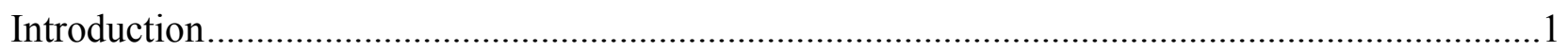

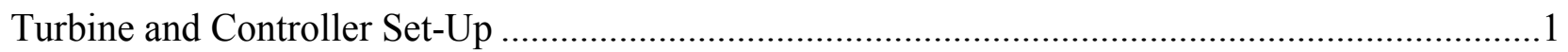

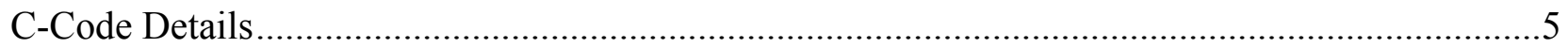

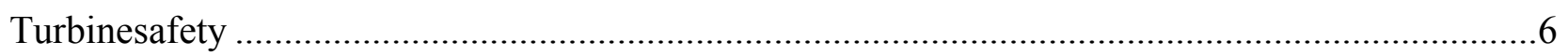

Solved and Unsolved Problems ..........................................................................................

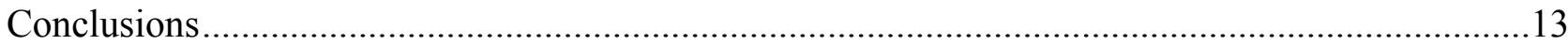

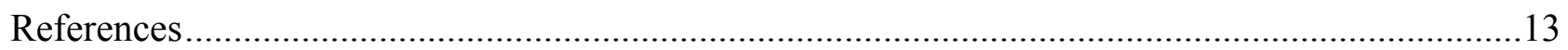

\section{Figures}

Figure 1. CART commanded torque vs. speed relationship .........................................................

Figure 2. CART's "Optimize Pitch as Low Tip-Speed Ratios" routine .............................................

Figure 3. CART's simulated operation under PI, PID, and PI/ID control with (a) step changes in wind speed, and (b) turbulent wind data ....................................................................

Figure 4. (a) High speed shaft RPM, (b) Blade Pitch Angle, (c) Tower Bending Moment (Nm), and (d) X Accelerometer Output for normal and emergency stops ...............................................

Figure 5. (a) Actual commanded and measured pitch rate, and (b) filtered commanded

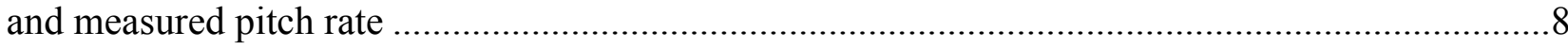

Figure 6. CART's commanded pitch rate and blade current before and after changing

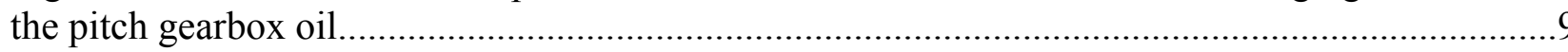

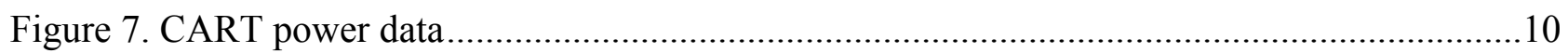

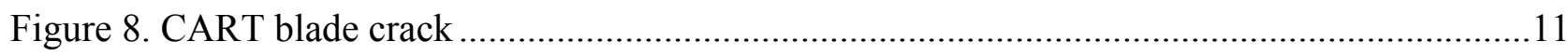

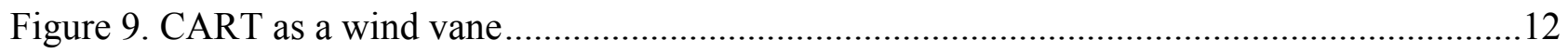

\section{Tables}

Table 1. CART Faults: Normal and Emergency Stops.............................................................. 


\section{Introduction}

The Controls Advanced Research Turbine (CART) has been installed at the National Wind Technology Center (NWTC) for several years now (Fingersh and Johnson 2002). During that time, we have encountered numerous problems while implementing several advanced control algorithms. We hope that by sharing some of these lessons we can assist others with implementation and testing of their own experimental controllers.

The CART is a $600-\mathrm{KW}$, 2-bladed, upwind, horizontal-axis wind turbine. It is $36.6 \mathrm{~m}$ tall at the axis of rotation and has a 43.3-m rotor diameter with full span blade pitch capability. Originally installed at Kahuku Point on the island of Oahu, Hawaii, it was moved in 1996 to the National Renewable Energy Laboratory's (NREL's) National Wind Technology Center in Golden, Colorado. Since then, we have used two baseline controllers and four types of advanced controllers (Hand et al 2004) for our experiments. Advanced control experiments included the use of generator torque to assist rotor speed tracking (Fingersh and Johnson 2004), the use of adaptive control to increase energy capture (Johnson 2004, Johnson et al 2004a, Johnson et al 2004 b, Johnson et al 2005), and the use of state-space controls in several different configurations to reduce loads. The state-space controls included Disturbance Accommodating Control (DAC) and Disturbance Tracking Control (DTC) with variations of constant or periodic gain pitch control and collective or individual pitch control (Stol and Fingersh 2004, Street et al 2004, Wright and Balas 2004, Wright et al 2005).

In this paper, we describe the turbine and controller set-up and some of the challenges we encountered with it. We also explain some of the peculiarities of the C-code we use to control the CART and discuss our fault protection routine, Turbinesafety, and some of its failures. Finally, we relate some of the general problems we have encountered during our three years of testing.

\section{Turbine and Controller Set-Up}

We can operate the CART in either constant-speed or variable-speed mode. As a research turbine, it is outfitted with many more sensors than would normally be installed on a wind farm turbine, including pressure transducers, torque transducers, strain gauges, thermometers, position encoders, accelerometers, anemometers, wind vanes, and power, current, and voltage meters. The output of each of these sensors is recorded at the control rate of $100 \mathrm{~Hz}$. In addition, the CART has two sensors installed inside the nacelle that we use to diagnose problems in real time. The first is a microphone, and the second is a remotely controlled video camera that is supplemented by a ball-and-string "accelerometer" hanging inside the nacelle. The ball and string accelerometer allows us to detect when a new controller excites a towerbending mode and to shut down the controller immediately rather than waiting to analyze a data set once the turbine has stopped.

Standard Control. The CART's "standard" control technique (Johnson 2004, Johnson et al 2004) was used in baseline variable-speed testing. This standard control is based on Proportional-Integral-Derivative (PIDpitch control in region 3 and the usual torque-speed curve in region 2. Operational regions are defined more clearly in our references, but, briefly, region 1 consists of the turbine start-up routine, region 2 comprises the time during which it is desirable that the turbine capture as much power as possible from the wind, and region 3 is encountered when the wind speeds are high enough that the turbine must limit the fraction of the wind power captured so that safe electrical and mechanical loads are not exceeded. Region 2.5 is a short 


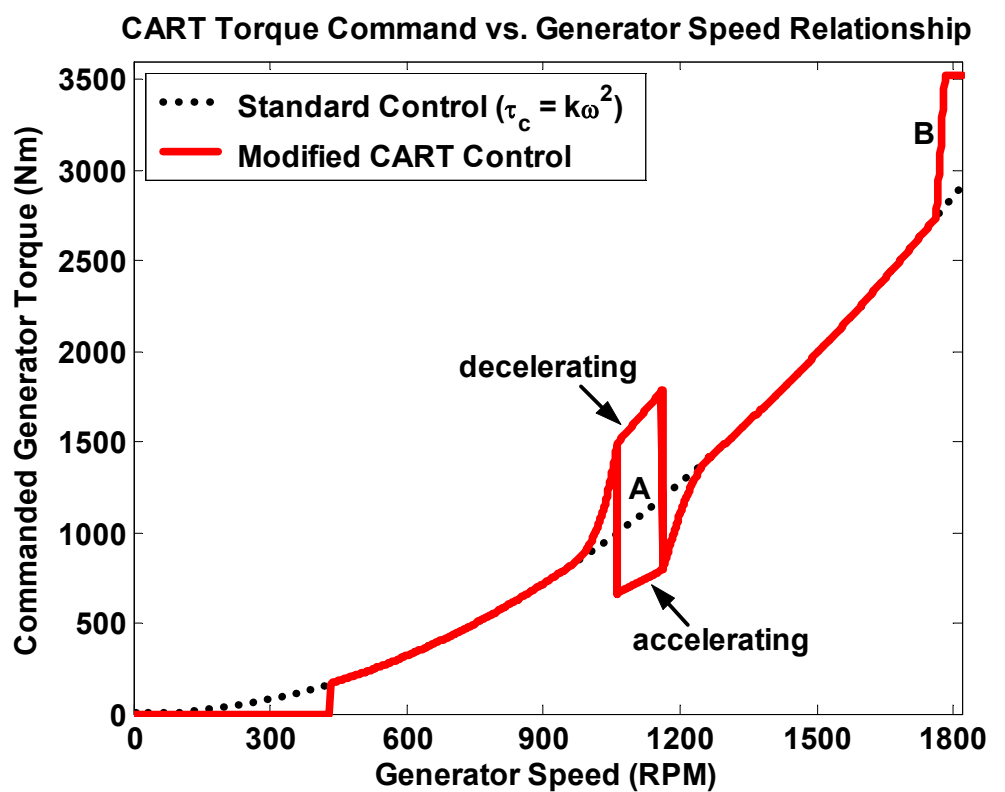

Figure 1. CART commanded torque vs. speed relationship. The CART uses a modified version of the standard control curve. Note the tower resonance avoidance technique centered at 1112 RPM and the linear curve connecting regions 2 and 3 at just below rated speed (1800 RPM).

connecting zone between region 2 and region 3 that we added to prevent a discontinuous torque control curve. Region 2.5 has a slope that represents an induction generator with a 5\% slip and connects the standard torque-speed curve to the rated torque, ending at $99 \%$ of rated speed. Our expected speed regulation error is $1 \%$, so ending region 2.5 at $99 \%$ of rated speed reduces the switching between controllers that would occur if region 2.5 ended at rated speed.

The standard torque-speed curve is given by

$\tau_{c}=K \omega^{2}$

$K=\frac{1}{2} \rho A R^{3} \frac{C_{p \max }}{\lambda_{*}^{3}}$.

However, the CART's region 2 and region 3 controllers are actually more complex than the standard control. We modified the standard torque control to avoid exciting the first towerbending mode and to link regions 2 and 3 at the rated speed and power. In addition, we modified the pitch control system to improve operation both at low tip-speed ratios and in the region $2-3$ transition.

CART Torque Control. Figure 1 shows the CART's torque command vs. speed relationship compared to the standard torque control (1). The commanded torque follows the bottom half of the hysteresis loop (A) at 1062-1162 RPM when the rotor is accelerating and the top half when it is decelerating. These modifications to the standard control reduce the excitation of the first tower-bending mode by reducing the time spent operating near the mode. In addition, the line segment (B) connecting the standard control curve (1) to the constant torque allows the CART to operate at its optimal tip-speed ratio in region 2 and to reach its rated power at its rated speed. Operation on line segment (B) corresponds to region 2.5.

CART Pitch Control. Figure 2 shows the relationship between commanded blade pitch and filtered tip-speed ratio in region 2 operation. When the filtered tip-speed ratio falls below 6.0 , we command the blade pitch to a value higher than the normal region 2 pitch value $\left(-1^{\circ}\right)$. 


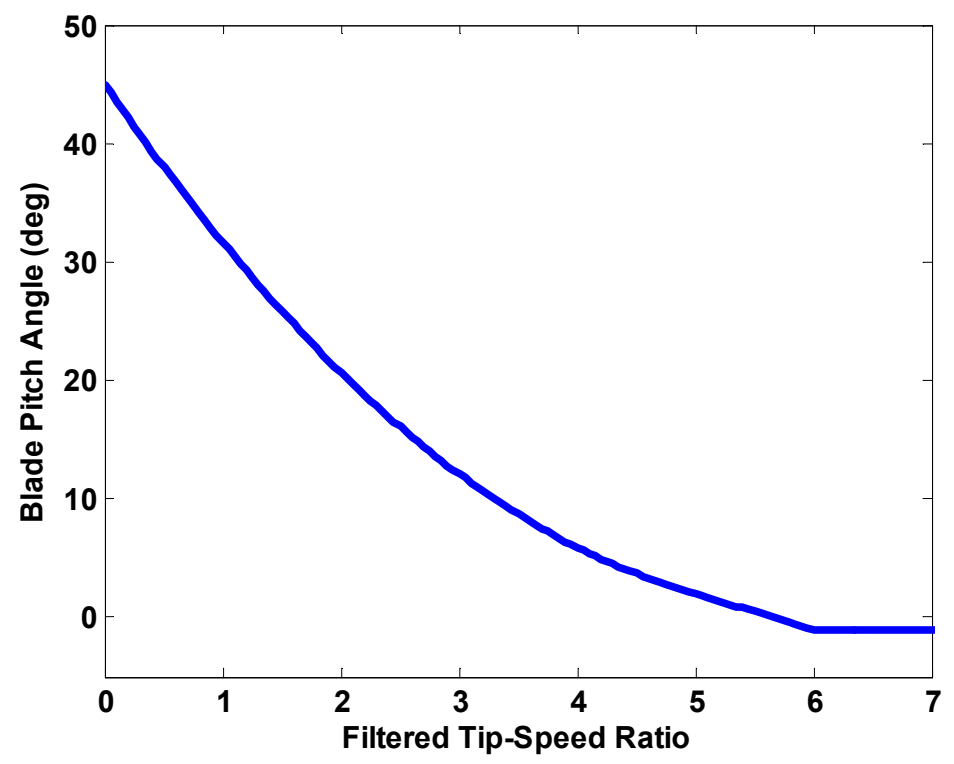

Figure 2. CART's "Optimize Pitch at Low Tip-Speed Ratios" routine. This plot shows the relationship between pitch and filtered tip-speed ratio used in region 2 operation when the filtered tip-speed ratio drops significantly below its optimal value.

The filter is a single pole, low pass filter. Not only does this technique improve the operation of the turbine by reducing the amount of time spent at sub-optimal tip-speed ratios, but it can also be essential to the start-up of the machine. During another test, we removed the optimize pitch routine and discovered that the turbine would no longer start. In lower wind speed regimes, the blades pitch from feather to run so quickly that there is no time for the aerodynamic torque to accelerate the rotor from the stopped position. When the blades are pitched to run and the rotor speed is close to zero, there is insufficient aerodynamic torque to overcome the friction and damping in the system.

A major difference between the CART's pitch control and the PID frequently used in region 3 is the fact that the CART uses a proportional, integral/integrated derivative (PI/ID) control. If the controller were continuous, this PI/ID control would be equivalent to a PI controller. However, for a discrete system, this is not the case. Although we developed the $\mathrm{PI} / \mathrm{ID}$ control by accident (via a coding error), we have come to appreciate its benefits, particularly the lack of rotor speed overshoot we observe when the turbine enters region 3 .

Figure 3 shows the results of six simulations performed for two different wind inputs using discrete PI, PID, and PI/ID control on a model of the CART. The equations used in the $\mathrm{PI} / \mathrm{ID}$ simulations are as follows:

$$
\begin{aligned}
& q_{k}=\frac{1}{T}\left(\psi_{k}-\psi_{k-1}\right), \\
& r_{k}=\left(1-e^{-4 T}\right) q_{k}+e^{-4 T} q_{k-1}, \\
& \widetilde{r}_{k}=r_{k}-r_{k}^{*}, \\
& \Delta \beta_{k}=\max \left[-1, \Delta \beta_{k-1}+k_{i} T \widetilde{r}_{k}+k_{d}\left(\widetilde{r}_{k}-\widetilde{r}_{k-1}\right)\right], \\
& \text { and } \beta_{k}=\max \left[-1, \Delta \beta_{k}+k_{p} \widetilde{r}_{k}\right],
\end{aligned}
$$



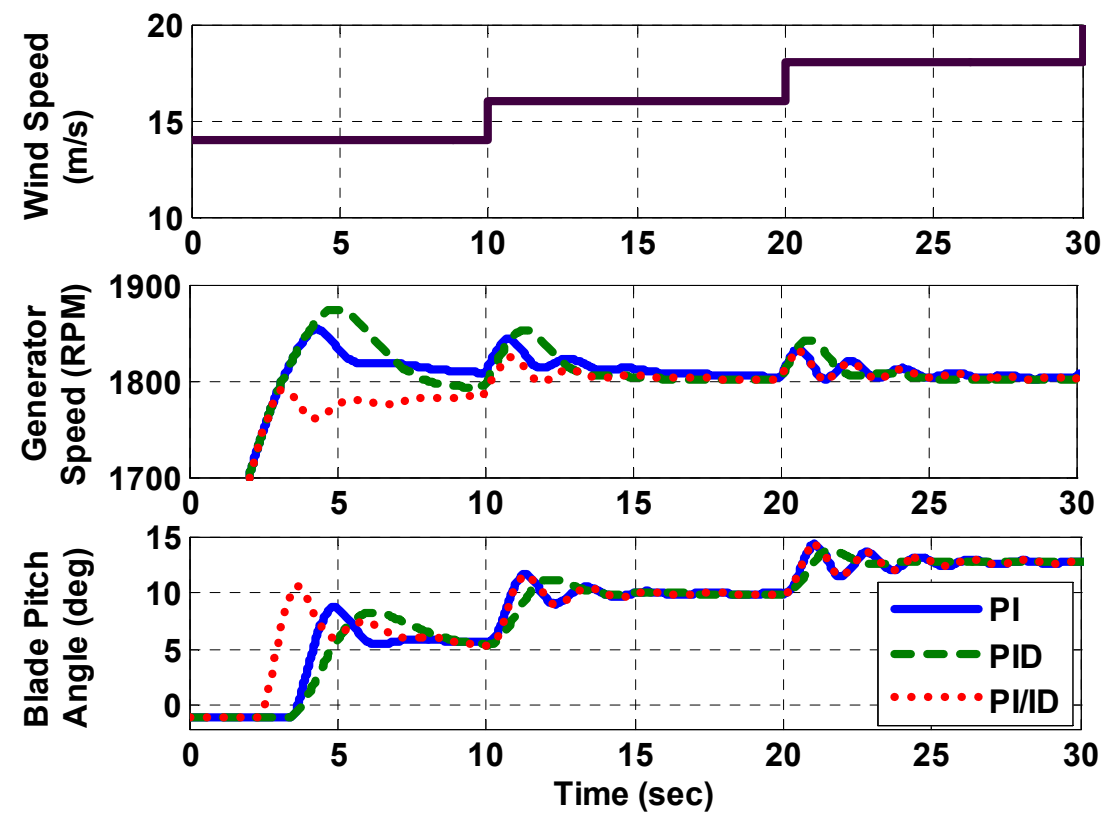

(a)
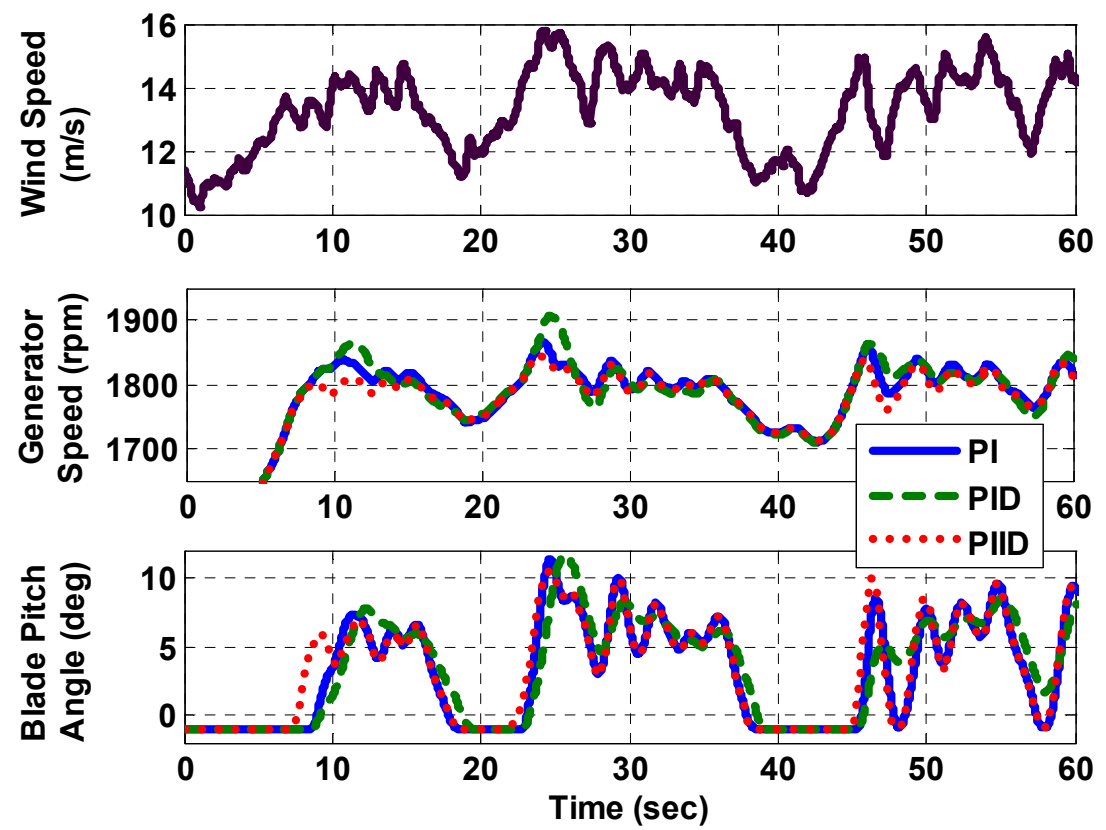

(b)

Figure 3. CART's simulated operation under PI, PID, and PI/ID control with (a) step changes in wind speed, and (b) turbulent wind data.

Note that the PI and PID controllers are not optimized but rather use the same gains that optimized the PI/ID control in the field.

where $q$ is the unfiltered discrete rpm calculation, $T$ is the time period $(0.01 \mathrm{~s}), \psi$ is the rotor azimuth position, $r$ is the filtered rotor rpm, $r^{*}$ is the desired rpm, $\widetilde{r}$ is the error between actual and desired rpm, $\Delta \beta$ is the incremental pitch from one time period to the next, $\beta$ is the pitch angle, the subscript ${ }_{k}$ denotes the discrete time step, and $k_{p}, k_{i}$, and $k_{d}$ are the proportional, integral, and derivative gains, respectively. Both (6) and (7) select the largest of the two values, 
which allows the controller to run throughout regions $2,2.5$ and 3 , saturating to a value of $-1^{\circ}$ when not in region 3.

The equations for the PID simulation are similar in that (3) - (5) remain the same while

(6) and (7) are modified to:

$$
\Delta \beta_{k}=\max \left[-1, \Delta \beta_{k-1}+k_{i} T \tilde{r}_{k}\right]
$$

and

$\beta_{k}=\max \left[-1, \Delta \beta_{k}+k_{p} \widetilde{r}_{k}+k_{d}\left(\widetilde{r}_{k}-\widetilde{r}_{k-1}\right)\right]$.

Finally, PI uses (3) - (5), (8), and

$\beta_{k}=\max \left[-1, \Delta \beta_{k}+\left(k_{p}+k_{d}\right) \tilde{r}_{k}\right]$.

Clearly, in these simulations the PI case is not simply the PID case with the derivative term, $k_{d}$, set equal to zero. Because we were trying to compare both the PI and PID case to the PI/ID case rather than to each other, it was important that we keep the proportional gain in the PI controller equal to the sum of the proportional and integrated derivative gains in the PI/ID control.

In Figure 3(a), we use a stepwise constant wind speed input, while in Figure 3(b) the wind speed input is taken from measured data. For each simulation, the turbine is initially in region 2 (pitch angle $=-1^{\circ}$ ), accelerating towards rated speed (1800 rpm). In both (a) and (b), the PI/ID controller is able to anticipate reaching rated speed, causing the blades to start pitching about a second earlier than the PI and PID controllers upon entry into region 3. This earlier pitching upon entering region 3 results in no overshoot of the rated speed for the stepwise constant wind input, and less overshoot than the PI and PID controllers for the turbulent wind input. Once the region $2-3$ transition transients are no longer significant, the PI/ID controller is equivalent to the PI controller.

Rotor Radius. After running all of the baseline tests on the turbine, we measured the rotor radius and discovered that the measurement shown in the manufacturer's drawings, $21.0 \mathrm{~m}$, was off nearly $3 \%$ compared to our measurement of the radius, $21.64 \mathrm{~m}$. Because the radius is raised to the fifth power in the standard torque control equation (2), this small error led to a significant error (14\%) in the torque control gain used in our baseline variable-speed controller. We considered this error and the fact that it may have led to sub-optimal operation when making future energy capture comparisons between the baseline controller and our advanced controllers.

\section{C-Code Details}

Because the CART is a research turbine, we use a versatile PC, which we call "Dataprimary," as our controller. We run Dataprimary in DOS, which gives us more stability than Windows, but we still employ hardware to take over and shut down the turbine in case of a computer failure. We perform most of the simulations involved in developing our advanced control techniques in Matlab's Simulink $\AA$, then transfer the code by hand into $\mathrm{C}$ and compile it onto Dataprimary. Problems we encountered during this code transfer, which we found to be more complex than it sounds, included:

- code length problems,

- stack length problems,

- making sure arrays and strings have sufficient length,

and others that are undoubtedly familiar to experienced programmers but not necessarily to wind turbine engineers. 
Integrated Simulator. To detect these and other errors that might not be caught by the compiler, we created a simulation tool within the turbine control program. This simulation tool contains a $C_{p}$-TSR-Pitch look-up table and allows us to observe the rotor speed as we vary the wind speed's mean and standard deviation along with the mean and standard deviation of the yaw angle. In addition to checking for reasonableness in the rotor speed and blade pitch angle, we can check for reasonableness in other sensed and controlled values, such as power, blade pitch, and yaw angle. When we observe unexpected outputs while running the simulation, we can check to ensure that we transferred the code correctly while looking for errors such as those listed above.

\section{Turbinesafety}

Our fault protection routine, Turbinesafety, provides three different levels of faults. The first is a warning, which does not stop the turbine but looks for possible non-critical sensor errors. Any detected problems are written to the data file along with the sensor outputs and control inputs. For example, sensor errors that trigger a warning include out of range teeter position, vastly different strain gauge readings over long periods from blade 1 to blade 2 , and errors between the high and low speed shaft rpm calculations.

The second fault level is a normal stop. These faults necessitate a stop in the turbine, where the stop is performed using PI/ID pitch control with a gradually decreasing rotor speed as the reference input. Once the rotor has slowed sufficiently, the blades are pitched at $5 \% \mathrm{~s}$ until they reach the feathered position. In general, normal stops are performed for serious faults that do not involve the pitch system but have the potential to damage the turbine if left uncorrected . Because the rotor brakes are not used in a normal stop, a normal stop might not succeed in stopping the turbine when there are problems with the pitch system.

The third fault level is an emergency stop. Emergency stops are performed for critical faults that could damage the turbine within seconds and those that involve the pitch system. In an emergency stop, we command the blades to pitch to feather as fast as possible, disable the power electronics, and set the emergency rotor brake, teeter brake, and yaw brake. While normal stops may take 30-60 seconds to stop the turbine while it operates at rated speed in region 3 winds, an emergency stop can stop the turbine in as little as 5 seconds. However, because emergency stops put so much stress on the machine, we regard them as last resorts. Table 1 lists the normal and emergency stops for which we test in the CART's software.

Normal and Emergency Stops. Figure 4 shows time-series plots for a normal stop and an emergency stop. Both have been plotted such that the stop occurs at time zero. We also removed the means from the accelerometer readings.

In Figure 4, the normal stop resulted from a teeter brake pressure problem and the emergency stop resulted from a blade pitch following error. In each case, the turbine was operating at just above rated speed (1800 RPM) when the fault occurred, as shown in subplot (a). During the normal stop, the pitch rate stayed low as the blades pitched towards feather in a controlled manner as shown in subplot (b). By contrast, during the emergency stop the blades pitched towards feather at the maximum pitch rate of $18 \%$, reaching a fully feathered position in about 5 seconds. The high-speed shaft RPM decreased correspondingly fast for the emergency stop. In terms of the loads observed by the turbine structure, both the tower bending and $\mathrm{x}$ acceleration plots show significant responses to the emergency stop. Neither of these channels showed similar jumps in magnitude at the time of the normal stop. However, it is apparent that the tower bending and $\mathrm{x}$ acceleration grew as the pitch reached about $25^{\circ}$ in the normal stop, 
Table 1. CART Faults: Normal and Emergency Stops

\begin{tabular}{|l|l|}
\hline \multicolumn{1}{|c|}{ Normal Stops } & \multicolumn{1}{c|}{ Emergency Stops } \\
\hline Power electronics digital outputs sensor failure & RPM sensor or gearbox failure \\
Gearbox over temperature & X, Y, or Z acceleration extremely high \\
Generator over temperature & Power electronics power too high \\
HSS or LSS torque sensor failure & Generator current too high \\
Rotor brake sensor failure & Generator voltage too high \\
Generator frequency sensor failure & Grid power outage \\
Gearbox oil pressure too low & Blade 1 pitch sensor failure \\
X, Y, or Z acceleration high & Blade 2 pitch sensor failure \\
Yaw brake set unintentionally & Blade 1 \& 2 pitch significantly different \\
& (collective pitch mode only) \\
Teeter brake set unintentionally & Overspeed \\
Extreme yaw error & Blade 1 or 2 not obeying the pitch rate \\
Adaptive gain M beyond reasonable limits & command \\
Power electronics drive not ready & \\
\hline
\end{tabular}

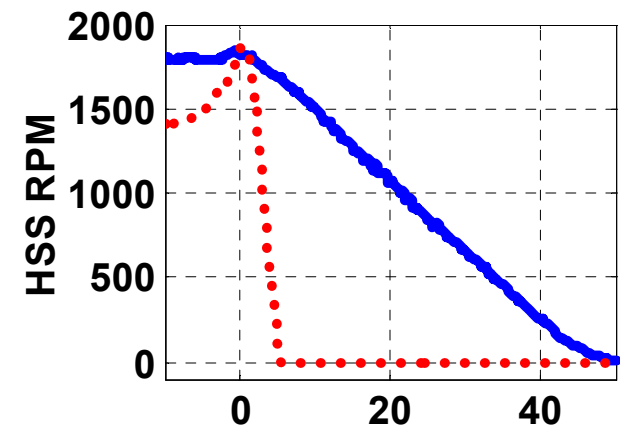

(a)

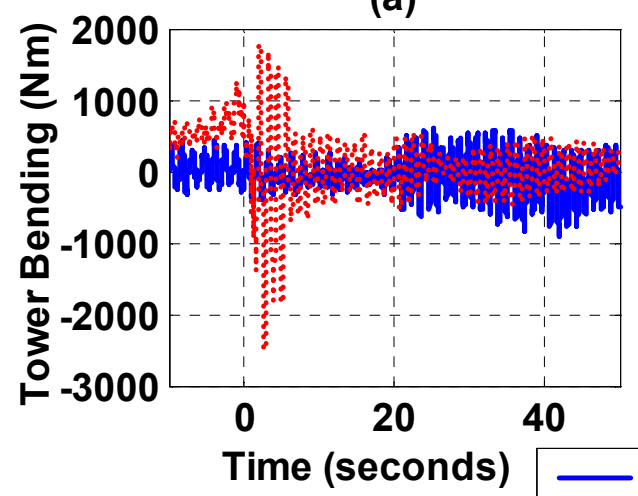

(c)

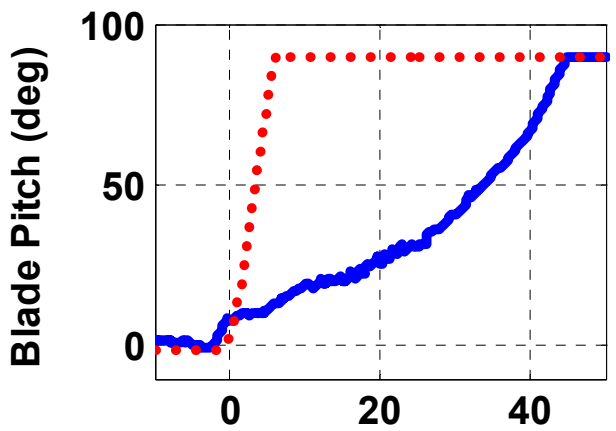

(b)
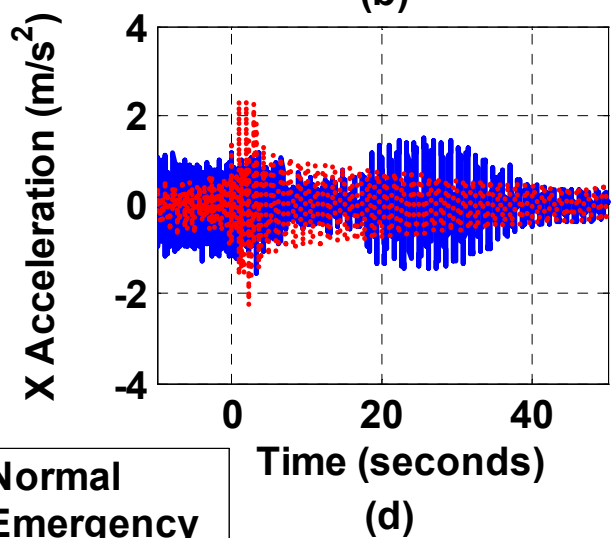

Figure 4. (a) High Speed Shaft RPM, (b) Blade Pitch Angle, (c) Tower Bending Moment (Nm), and (d) X Accelerometer Output for normal and emergency stops. The emergency stop is harder on the turbine.

though the magnitudes are less than for the emergency stop case. These vibrations are expected for a shutdown in high winds. 

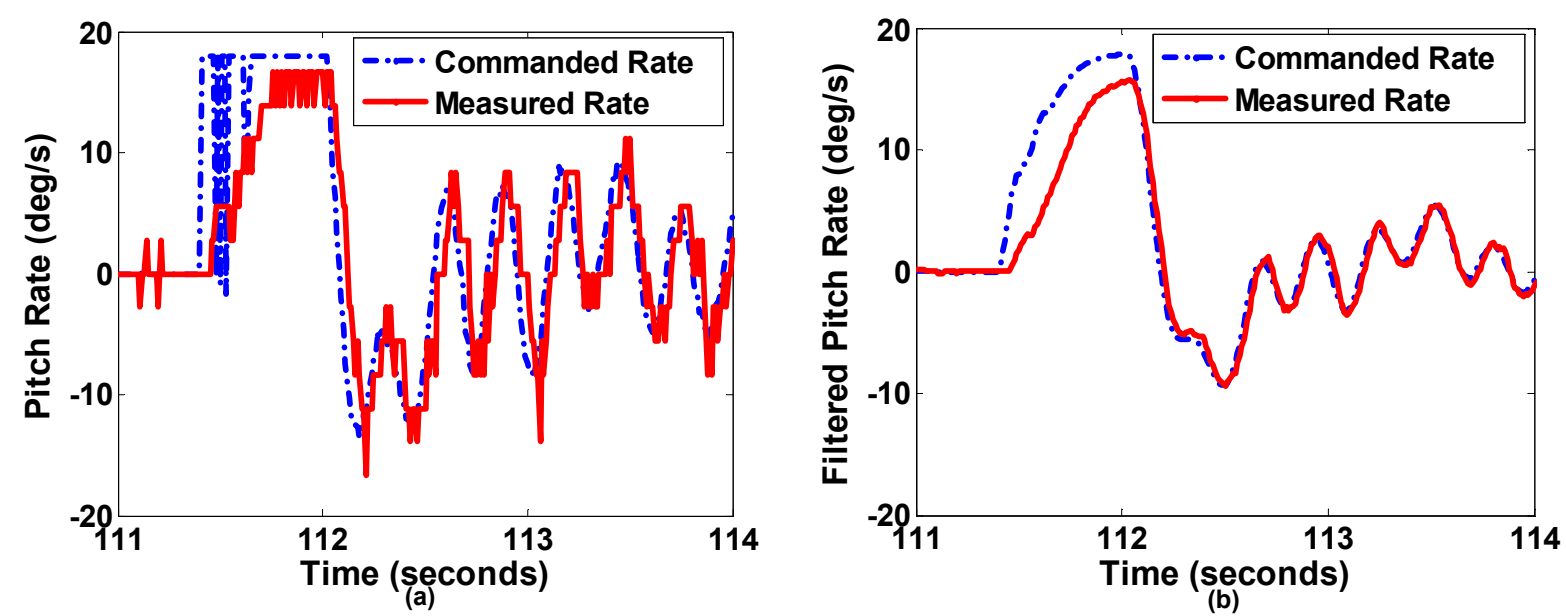

Figure 5 (a) Actual commanded and measured pitch rate, and (b) filtered commanded and measured pitch rate. The maximum pitch rate is $18 \%$ s. The measured rate in (a) clearly lags behind the commanded due to actuator lag, even when the rates are low (from 112 - 114 seconds). In (b), the actuator lag is included as a second pole in the filtered commanded rate, causing the two curves to be very close when commanded pitch rates are modest.

Development of a Pitch Rate Error Fault. Turbinesafety has been a work in progress since the early days of the CART commissioning and baseline data collection. While some faults, like overspeed and high accelerometer readings, are easy to detect, others, such as pitch problems, are more complex. In Table 1, five of the faults listed relate to the pitch system. The fourth fault, "Blade 1 or 2 not obeying the pitch rate command," has required many revisions and may require more in the future. As a result of actuator dynamics, saturation, and encoder quantization errors, we found it difficult to detect real errors in the pitch rate without triggering nuisance faults in various operational regimes

Figure 5 contains two plots showing pitch rate and filtered pitch rate for 3 seconds of CART data. In Figure 5(a), the actual commanded pitch rate and measured rate are shown to differ, and the actuator lag is clear. In addition, the quantization error in the position encoder is apparent in the measured rate, which is calculated from this sensor. In Figure 5(b), the pitch rate command has been filtered twice and the measured rate once. In the moderate pitch rate section of the plot, the two curves nearly coincide. When the commanded pitch rate is near its $18 \% \mathrm{~s}$ limit, however, the actual (measured) rate is unable to keep up.

The two curves in Figure 5(b) are the two primary signals used in our pitch rate following fault. The error tolerance is based on the commanded rate, so that a larger error is allowed when the rate command is higher. In addition, if the pitch drive current is at its limit, the filtered rate error is not required to lie within the error bound as long as the pitch acceleration has the correct sign. Analysis of many hours of operational data have shown that our technique will detect a fault within a couple of seconds, or much faster for most types of faults, but it rarely results in nuisance faults when the pitch system is behaving properly.

Detection of Actual Pitch Following Fault. Shortly after we implemented the current version of the pitch rate following fault, the fault started to occur regularly on start-up and we immediately assumed that a poorly written fault routine was causing nuisance faults. Further data analysis revealed odd behavior in the pitch system: even when the commanded pitch rate was well within the capability of the CART's pitch actuators, the actuators would draw the full current allowable, while still not following the commanded rate closely. The amount of current drawn decreased as the pitch system was used for longer time periods, which led us to believe 

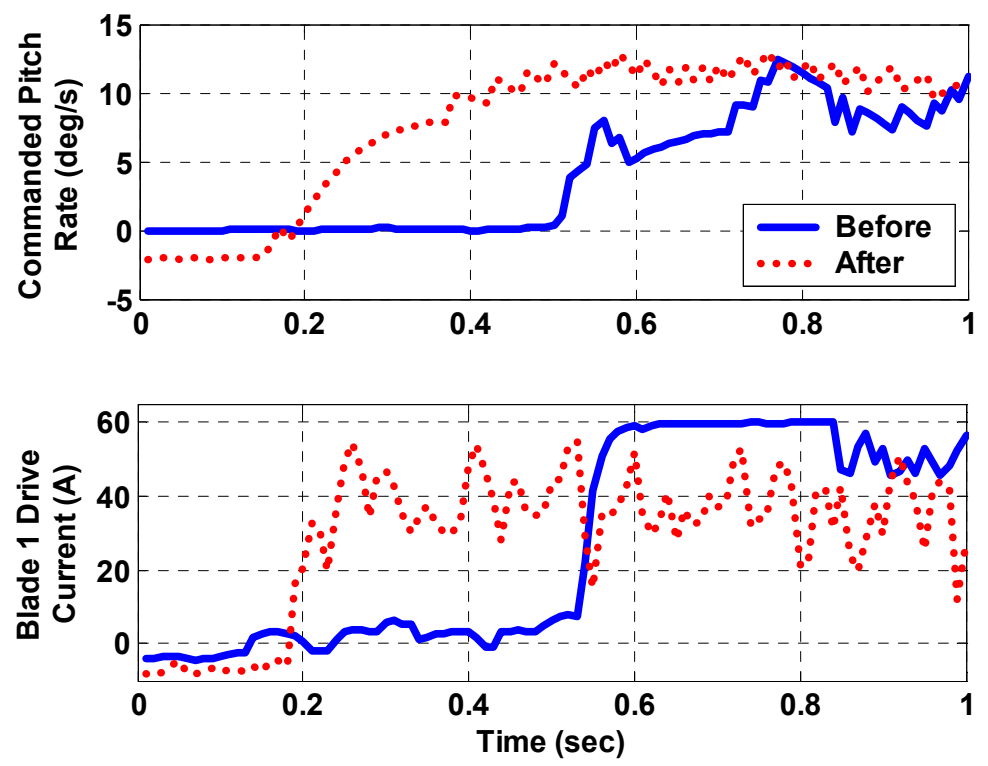

Figure 6. CART's commanded pitch rate and blade current before and after changing the pitch gearbox oil. We discovered that the oil we had been using was much too viscous, causing the pitch drive motors to draw high currents until the gearbox warmed up.

that the cause of the high current was temperature-related. After examining the system, we discovered that the oil viscosity in the pitch gearbox was significantly higher than recommended by the gearbox manufacturer (molasses vs. WD-40). In fact, we had been using the wrong oil since the turbine was installed but had never noticed because our fault detection software was not sophisticated enough during the first few years of operation. Figure 6 shows plots of the commanded pitch rate, which has an $18^{\circ}$ s limit on the CART, and pitch drive current before and after changing the gearbox oil. Both cases occurred near turbine start-up when the gearbox oil temperature would have been close to ambient. Clearly, changing the oil allowed for less current to be drawn, even with slightly higher commanded pitch rates.

Other Solutions. Even though we have managed to implement a safety measure for the pitch rate error fault, we speculate that it might be better in some situations to limit the control to a signal that is attainable by the CART's hardware. For example, though we have a limit on the controlled pitch rate, we lack one on the controlled acceleration. Thus, we can and do demand accelerations of $1800^{\circ} / \mathrm{s} / \mathrm{s}$ (from $0^{\circ} / \mathrm{s}$ to $18^{\circ} / \mathrm{s}$ in $0.01 \mathrm{~s}$ ) from the CART's pitch drives. Since we know this acceleration is impossible for the CART pitch actuators, we wonder whether we should limit it to more reasonable values. In other words, should the calculation of high pitch rate errors caused by impossible commands be eliminated via more sophisticated Turbinesafety algorithms or in the turbine's controller by commanding only attainable rates and accelerations?

\section{Solved and Unsolved Problems}

During the course of testing on the CART, we have experienced many sensor failures. While some failures were easy to fix, we could not identify the cause or find solutions for others. Two unsolved sensor failures relate to a speed sensor on the high-speed shaft ("HSS Prox") and a power sensor on the generator ("Generator Power"). The HSS Prox sensor worked as expected during the CART's initial constant-speed tests, but gave a very noisy signal during the initial 


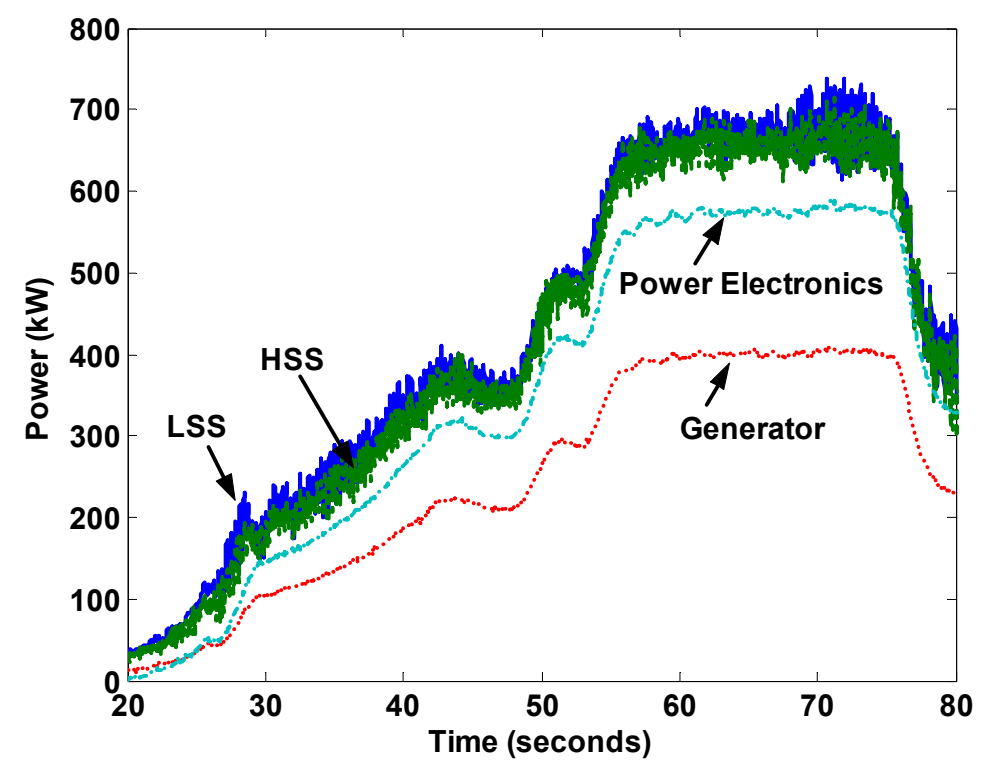

Figure 7. CART power data. The generator power curve is much lower than possible compared to the LSS, HSS, and power electronics power readings.

variable-speed testing. Because the power electronics were energized in variable-speed mode but not in constant-speed mode, and the erroneous HSS Prox readings corresponded exactly to the variable-speed operation, we concluded that the noise resulted from the power electronics. However, we were unable to shield the signal or find another means to eliminate the noise problem, so instead we stopped reading the sensor. The high-speed shaft speed was already being calculated from the high-speed shaft position encoder, so the HSS Prox sensor was really unnecessary.

Generator Power Sensor Failure. The cause of the generator power sensor failure is likely related to the power electronics as well, because the failure corresponded to the transition from constant-speed to variable-speed testing. We know the power sensor measurements are erroneous because they show lower generator power levels than those measured at the power electronics further down the line. The power electronics power measurements are consistent with the high- and low-speed shaft power measurements, given the expected losses. Figure 7 shows the four time-series power plots, with the power electronics power being nearly $50 \%$ greater than the generator power. Since it is impossible to create power between the generator and power electronics, the generator power sensor is clearly wrong.

Because both the HSS Prox sensor and Generator Power sensor are redundant, we spent less time trying to fix the problems than we would have if there were no other sensors performing the same or similar measurements. However, we caution that the data from these two sensors should be ignored in those data files in which it is present.

Blade Crack. Another problem we encountered with the CART was a crack in one of the blades near the root. Figure 8 shows the $59 \mathrm{~cm}$ crack, which we noticed during a routine inspection. While we do not know what caused the crack (i.e., a sudden event or wear and tear over time), we determined that the crack was only deep enough to damage the blade's external coating. After researching our options for repairing the damage, we decided that, as the crack did not pose a structural risk to the blade, it could be repaired it by filling and covering it. We 


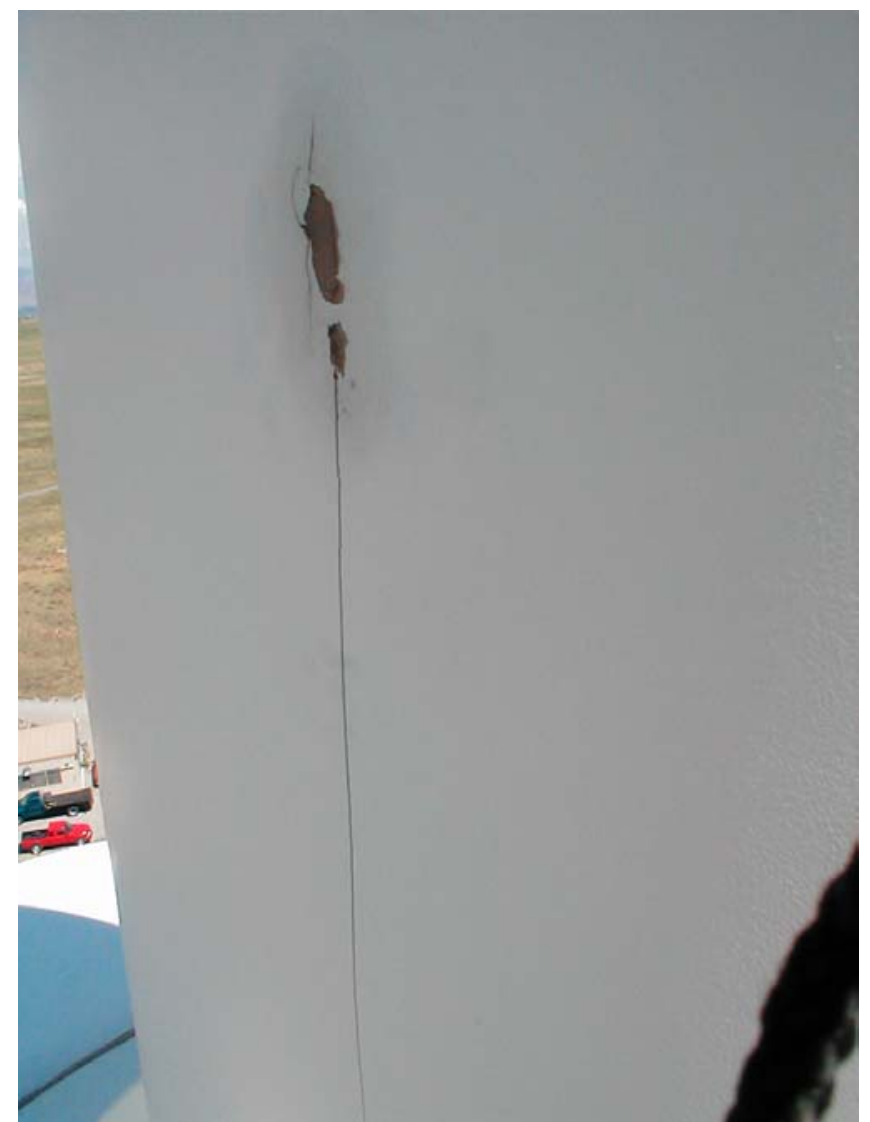

Figure 8. CART blade crack. The total crack length is approximately $59 \mathrm{~cm}$.

have run the turbine for more than a year since the repairs were completed and have seen no indicators that it has gotten worse.

Rotor Positioning for Calibration. The CART has a fairly large rotational inertia, which makes positioning the rotor for calibrations a challenge. Fortunately, we can use its induction generator as a motor, so we designed a PID controller to position the rotor at any desired azimuth position. The PID controller takes azimuth error as its input and controls generator torque as its output. We limit the generator torque to $10 \%$ of its rated value to prevent excessive speeds during calibration routines. While this PID controller performs well for a balanced rotor, for pitch and blade strain gauge calibrations we must install a jig on one blade, which causes the rotor to become unbalanced. In the case of the unbalanced rotor, $10 \%$ of rated torque is not always sufficient for positioning the blades. In addition, nonlinear effects, such as gear backlash, can become more of a problem when the rotor is unbalanced than when it is balanced.

Fortunately, we do not run the turbine with the jig installed, so the rotor unbalance is only a consideration for the rotor positioning controller.

Extreme Wind Event Failure. On December 20, 2004, we observed a high-wind failure event that began when the NWTC lost grid power because of high winds in the early morning before working hours. Although the main NWTC buildings have back-up generators, the turbine grid does not; thus, the CART's Turbinesafety routine performed an emergency stop in response to the power outage. As desired, the blades pitched to feather and the emergency brake set. By chance, the rotor stopped at a near-vertical azimuth position. The mean yaw error was near zero, 


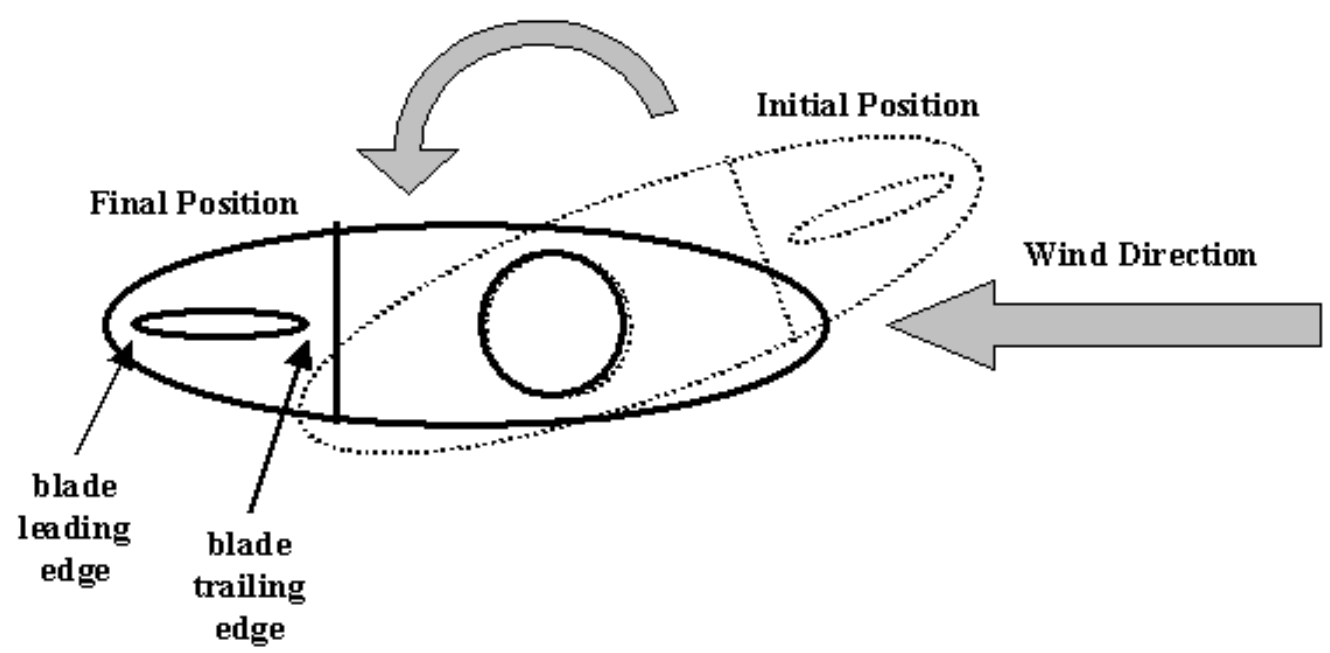

Figure 9. CART as a wind vane (top view). A small initial yaw error, locked rotor, near-vertical azimuth position, blades pitched to feather, and yaw brake failure resulted in the nacelle being pushed by strong winds to point downwind.

though not exactly. In all of these respects, the turbine had behaved properly and the situation was similar to ones the CART had experienced in the past.

We arrived on site within about 30 minutes of the grid power failure. Although the CART's data acquisition system does not collect data when the turbine is stopped, the data provided by the other anemometers at the NWTC showed mean wind speeds of almost $35 \mathrm{~m} / \mathrm{s}$ and peak gusts of more than $50 \mathrm{~m} / \mathrm{s}$ at a $10 \mathrm{~m}$ height. The peak speed at $80 \mathrm{~m}$ was similar to that at $10 \mathrm{~m}$. Noting the CART's locked and shut-down state, we left the turbine as it was and waited for the wind speed to decrease. Within an hour, however, we realized that the CART was yawing and went to check on the cause. The yaw brake pressure had decreased from its normal 2000 psi to 600 psi and could not be charged because it needed power from the grid, which was still unavailable. In addition, the emergency yaw brake had very low pressure. Because the rotor was locked in a near-vertical position with the blades pitched to feather, the CART was behaving like an oversized wind vane and was being pushed downwind by the strong winds. Figure 9 shows the CART in its approximate initial (dotted) and final (solid) position relative to the wind direction.

The CART's pitch system is not designed to endure large forces directed at the blade trailing edges. However, because we did not have the power required to reset the yaw brake or yaw the machine back upwind, our options were limited. One possibility was to release the rotor brake, let the rotor spin, and try to reset it when the azimuth position was near horizontal. This would have reduced the wind-vane effects compared to the vertically-positioned rotor, but the nacelle had already yawed halfway downwind and the side loading of the nacelle itself may have been enough to push it the rest of the way. In this case, the blades would still have been loaded from the trailing edges. Because we did not yet understand why we had lost pressure in the yaw brake, we were hesitant to release the rotor brake for fear that we would be unable to reset it. Thus, we again decided to wait.

When the wind calmed down, we found the CART was undamaged, and we discovered two failures in our yaw brake system. The first was our failure to connect the yaw brake to the uninterruptible power supply (UPS) that provides energy to most of the CART's critical components in emergency situations. The second was our failure to understand that the 
emergency yaw brake pressure system required manual recharging. We believed it recharged itself automatically, and therefore, the system had not been recharged in years. In the end, we corrected these failures and felt fortunate that these lessons did not come at a much higher cost.

\section{Conclusions}

In the process of installing, calibrating, and running various control schemes on the CART, we encountered numerous problems and solved many of them. In this report, our intent was to share these problems, both solved and unsolved, with other researchers in the wind industry. We hope that our remarks will help new experimentalists set up their own testbeds more efficiently and avoid some of the challenges we have faced.

\section{References}

Fingersh, L. and Johnson, K., 2002, Controls Advanced Research Turbine (CART) Commissioning and Baseline Data Collection. NREL Report No. TP-500-32879.

Fingersh, L. and Johnson, K., 2004, "Baseline Results and Future Plans for the NREL Controls Advanced Research Turbine," Proceedings of the 23rd ASME Wind Energy Symposium, Reno, NV, pp. 87-93.

Hand, M., Fingersh, L., Johnson, K., and Wright, A., 2004, "Advanced Control Design and Field Testing for Wind Turbines at the National Renewable Energy Laboratory," Proceedings of the World Renewable Energy Congress VIII, Denver, CO.

Johnson, K., 2004, Adaptive Torque Control of Variable Speed Wind Turbines, Ph.D. Thesis, University of Colorado, Boulder, CO.

Johnson, K., Fingersh, L., Balas, M., and Pao, L., 2004(a), "Methods for Increasing Region 2 Power Capture on a Variable Speed Wind Turbine," Journal of Solar Energy Engineering, Vol. 126, No. 4, pp. 1092-1100.

Johnson, K., Pao, L., Balas, M., Kulkarni, V., and Fingersh, L., 2004(b), "Stability Analysis of an Adaptive Torque Controller for Variable Speed Wind Turbines," Proceedings of the Conference on Decision and Control.

Johnson, K., Fingersh, L., Pao, L., and Balas, M., 2005, “Adaptive Torque Control of Variable Speed Wind Turbines for Increased Region 2 Energy Capture," Proceedings of the $24^{\text {th }}$ ASME Wind Energy Symposium, pp. 66-76.

Stol, K. A.; Fingersh, L. J. (2004). "Wind Turbine Field Testing of State-Space Control Designs: August 25, 2003--November 30, 2003.” NREL Report No. SR-500-35061.

Street, B. M.; Balas, M.; Stol, K. (2004). "Periodic and Non-Periodic Disturbance Accommodating Control of the Controls Advanced Research Turbine (CART)." Proceedings of the 23 ${ }^{\text {rd }}$ ASME Wind Energy Symposium; pp. 124-132.

Wright, A. D.; Balas, M. J. (2004). "Design of Controls to Attenuate Loads in the Controls Advanced Research Turbine. Journal of Solar Energy Engineering, Vol. 126, No. 4; pp. 1083-1091.

Wright, A. D.; Fingersh, L. J.; Stol, K. A. (2005). "Progress in Implementing and Testing StateSpace Controls for the Controls Advanced Research Turbine," Proceedings of the $24^{\text {th }}$ ASME Wind Energy Symposium, pp. 88-100. 


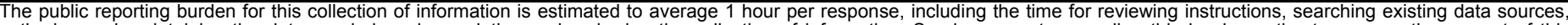

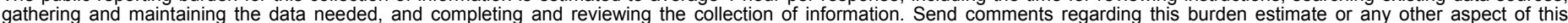

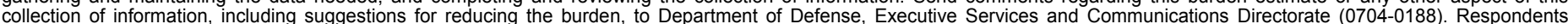

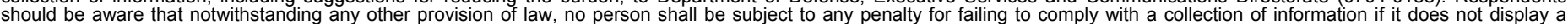

should be aware that notwithstanding

PLEASE DO NOT RETURN YOUR FORM TO THE ABOVE ORGANIZATION.
1. REPORT DATE (DD-MM-YYYY) June 2005
4. TITLE AND SUBTITLE
Controls Advanced Research Turbine: Lessons Learned during Advanced Controls Testing

3. DATES COVERED (From - To) 2002 - 2005

5a. CONTRACT NUMBER

DE-AC36-99-G010337

5b. GRANT NUMBER

5c. PROGRAM ELEMENT NUMBER

5d. PROJECT NUMBER

NREL/TP-500-38130

5e. TASK NUMBER

WER53112

5f. WORK UNIT NUMBER
7. PERFORMING ORGANIZATION NAME(S) AND ADDRESS(ES)

National Renewable Energy Laboratory

1617 Cole Blvd.

Golden, CO 80401-3393
8. PERFORMING ORGANIZATION REPORT NUMBER

NREL/TP-500-38130

9. SPONSORING/MONITORING AGENCY NAME(S) AND ADDRESS(ES)

10. SPONSOR/MONITOR'S ACRONYM(S) NREL

11. SPONSORING/MONITORING AGENCY REPORT NUMBER

12. DISTRIBUTION AVAILABILITY STATEMENT

National Technical Information Service

U.S. Department of Commerce

5285 Port Royal Road

Springfield, VA 22161

13. SUPPLEMENTARY NOTES

14. ABSTRACT (Maximum 200 Words)

This paper describes some of the problems encountered while conducting tests on the Controls Advanced Research Turbine installed at the National Wind Technology Center. It also discusses some of the peculiarities of the C-code used to control the CART and discusses the fault protection routine, Turbinesafety, and some of its failures.

15. SUBJECT TERMS

Controls Advanced Research Turbine; CART; National Wind Technology Center; wind turbine testing

\begin{tabular}{|c|c|c|}
\hline $\begin{array}{l}\text { a. REPORT } \\
\text { Unclassified }\end{array}$ & $\begin{array}{l}\text { b. ABSTRACT } \\
\text { Unclassified }\end{array}$ & $\begin{array}{l}\text { c. THIS PAGE } \\
\text { Unclassified }\end{array}$ \\
\hline
\end{tabular}

\begin{tabular}{|c|c|}
\hline $\begin{array}{l}\text { 7. LIMITATION } \\
\text { OF ABSTRACT }\end{array}$ & $\begin{array}{l}\text { 18. NUMBER } \\
\text { OF PAGES }\end{array}$ \\
\hline UL & \\
\hline
\end{tabular}

19a. NAME OF RESPONSIBLE PERSON

19b. TELEPHONE NUMBER (Include area code) 